\title{
CHEAP AND IMMERSIVE VIRTUAL REALITY: APPLICATION IN CARTOGRAPHY
}

\author{
L. Herman ${ }^{1 *}$, O. Kvarda ${ }^{1}$, Z. Stachoň ${ }^{1}$ \\ ${ }^{1}$ Department of Geography, Faculty of Science, Masaryk University, Kotlářská 2, 61137 Brno, The Czech Republic - \\ herman.lu@mail.muni.cz,451448@mail.muni.cz,14463@mail.muni.cz
}

\author{
Commission IV, WG IV/9
}

KEY WORDS: 3D visualization, Carthoreality, evaluation, headset, low-cost virtual reality, Unity, user study.

\begin{abstract}
:
In this paper, we analysed and tested the possibilities for the use of low-cost VR (Virtual Reality) headsets, with a focus on cartographic visualization. Low-cost devices were compared and classified into three categories (low-end, mid-range and high-end). We also created a pilot virtual environment, called "Carthoreality", and conducted simple pilot user testing using this virtual environment and the three low-end headsets. Our pilot test shows a few drawbacks to these devices, including weight of the headset and penetrating light. Some problems in terms of user aspects were also identified, such as nausea while wearing headsets or disorientation after removing them, which occurred for all users.
\end{abstract}

\section{INTRODUCTION}

Although the term Virtual Reality (VR) was first used in 1989, and related technologies have been used since the 1950s and 1960s, VR was not made available to the general public until after 2010. VR is described as a computer-simulated environment with which, and within which, people can interact, and it can simulate physical presence in locations in the real world or imagined worlds (Riva, 2006; Stojšić et al., 2017).

We focused on low-cost devices for creating and mediating VR, especially on headsets, which should provide an immersive virtual reality experience and which are, at the same time, relatively cheap and affordable. These headsets, and VR in general, are currently used for many different purposes and in various applications, including archaeology (Chmelík and Jurda, 2017; Liarokapis et al., 2017), architecture (Portman et al., 2015), medicine (Li et al., 2017), engineering and design (Coburn et al., 2017), education (Kovalčík et al., 2012; Juř́k et al., 2016; Moskal and Choate, 2017), the game industry (Shepherd and Bleasdale-Shepherd, 2009; Chądzyńska and Gotlib, 2015), etc. The use of VR has also increased in geosciences, for example in spatial and urban planning (Herbert and Chen, 2015; Portman et al., 2015), crisis management (Kubíček et al., 2011; Bandrova et al., 2012; Herman et al., 2017), noise mapping (Herman and Řezník, 2015), teaching geography (Stojšić et al., 2016; Carbonell and Saorín, 2017), cartography (Juř́k et al., 2017; Kubíček et al., 2017) and

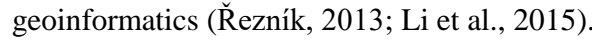

This study consists of three main parts. In the first part, available low-cost devices were compared and classified into three categories: low-end, mid-range and high-end; and available software tools had been summed up. In the second part, we created a pilot virtual environment called "Carthoreality". In the third part we conducted simple pilot user testing using our virtual environment and the three selected headsets. In the conclusion, we discuss the advantages and limitations of the created virtual environment and also the pilot study.

\section{LOW-COST VIRTUAL REALITY}

Under the term 'low-cost virtual reality', we most often imagine the synergy of three components: smartphone, software, and headset. The smartphone serves as the main processing and visualisation unit. Its main disadvantage is the lack of screen resolution and its insufficient processing performance. However, freedom of movement and portability are provided by the use of smartphones. The software refers to a variety of interactive VR applications, presentations, and $360^{\circ}$ videos. Finally, the headset itself serves, at least within low-cost VR, rather as a mere holder with a pair of optical lenses.

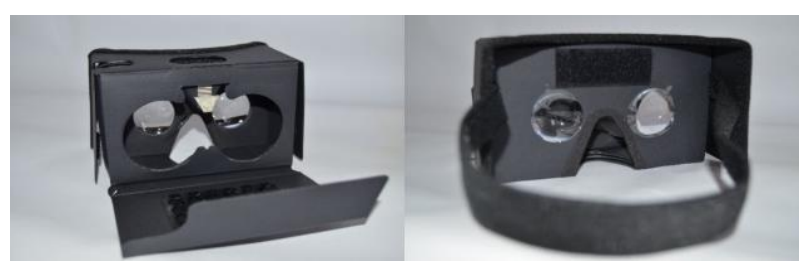

Figure 1. Google Cardboard Splaks 3D VR.

The milestone in this type of VR was Google's Google Cardboard introduction in 2014. The entire Google Cardboard platform consists of cardboard packaging, a pair of optical lenses, rubber bands, Velcro fasteners, and a small magnet that uses a built-in smartphone magnetometer as a primitive button. After the initial success of Google Cardboard, a number of other companies began to develop and produce cheap headsets for mobile devices (Coburn, et al., 2017; Ripton, 2014). For example, the company Samsung launched its own platform under the name of Samsung Gear VR in 2015 (Faulkner, 2018).

\footnotetext{
* Corresponding author
} 


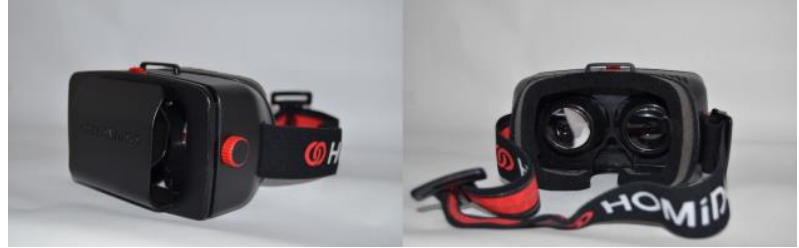

Figure 2. Homido VR.

Low-cost headsets are usually classified into three categories: low-end, mid-range, and high-end. We tested three low-end headsets: Google Cardboard Splaks 3D VR (see Fig. 1), Homido VR (Fig. 2) and BoboVR Z4 (Fig. 3). The selected headsets represent low-end and mid-range categories, which usually use the smartphone display for visualisation. For all three devices which we analysed, whether they have integrated IMU (Inertial Measuring Unit), adjustable optics, tracking and motion sensor, or other, non-technological properties such as price. The results of this analysis are presented in Table 1, where the parameters of the abovementioned headsets are compared with Oculus Rift HMD (Head Mounted Display), which represents the high-end category of headsets.

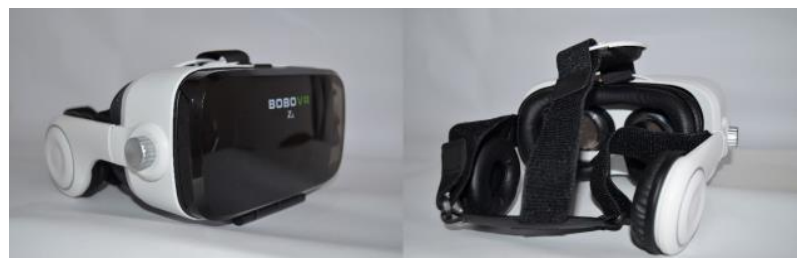

Figure 3. BoboVR Z4.

The biggest disadvantage of low-cost headsets, in general, is the absence of the tracking and motion sensors that we can find on more expensive HMD devices (such as Oculus Rift or HTC Vive). This disadvantage is most noticeable when using the headset for a longer period of time, when drift occurs, depiction is blurred and refresh rate of the image is slower than the head movements. Even the depiction changes its orientation, and it is necessary to restart the software application or calibrate the gyroscope.

\begin{tabular}{|c|c|c|c|}
\hline & Low-end & Mid-range & High-end \\
\hline Integrated IMU & No & Some & Yes \\
\hline $\begin{array}{l}\text { Tracking and } \\
\text { motion sensor }\end{array}$ & No & No & Yes \\
\hline $\begin{array}{l}\text { Adjustable } \\
\text { optics }\end{array}$ & Some & Yes & Yes \\
\hline $\begin{array}{l}\text { Integrated } \\
\text { LCD display }\end{array}$ & No & No & Yes \\
\hline Processing unit & Smartphone & Smartphone & $\mathrm{PC}$ \\
\hline $\begin{array}{l}\text { External } \\
\text { energy source }\end{array}$ & No & Some & Yes \\
\hline Input & $\begin{array}{l}\text { Button on } \\
\text { headset, or } \\
\text { none }\end{array}$ & Included & Included \\
\hline Price & $\$ 5-\$ 30$ & $\$ 30-\$ 100$ & $\$ 300-\$ 600$ \\
\hline $\begin{array}{l}\text { Examples of } \\
\text { devices }\end{array}$ & $\begin{array}{c}\text { Google } \\
\text { Cardboard } \\
\text { Splaks 3D VR, } \\
\text { Homido VR }\end{array}$ & BoboVR Z4 & $\begin{array}{c}\text { Oculus Rift } \\
\text { HMD }\end{array}$ \\
\hline
\end{tabular}

Table 1. Comparison of low-cost headsets.
Another disadvantage of some low-cost headsets is the common, but not ubiquitous, use of plastic lenses, which cannot equal glass lenses for their optical properties. The physical construction and headset materials can also have a major impact on the potential penetration of light into the headset's "chamber" and on the smartphone display.

\section{SOFTWARE TOOLS FOR LOW-COST VR}

In order to create the virtual environment itself, it is necessary to create such an environment first, specifically to 3D model it, and then to import this model into software that conveys the VR itself (virtual movement, interaction, etc.). Software primarily designed for computer graphics, computer-aided drawing (CAD), photogrammetry or GIS (Geographic Information System) can be used for 3D modelling virtual environments. 3D GIS software includes, for example, Esri ArcGIS with the 3D Analyst extension (includes modules ArcScene and ArcGlobe); Esri City Engine, which is based on procedural modelling principles; or Safe Software FME. CAD programs working with 3D data are, for example, Trimble SketchUp or FreeCAD.

Regarding software for 3D computer graphics, the commercial Autodesk 3D Studio MAX, Cinema 4D and Rhinoceros 3D are often used. However, there are also freeware applications like MeshLab, Wings 3D or the widely-used open source tool Blender. A number of plug-ins can be installed into Blender, one of them being BlenderGIS. BlenderGIS extends Blender to basic GIS features and tools; for example, the import of SRTM (Shuttle Radar Topography Mission) or OSM (Open Street Map) data, or support of the Shapefile format and WGS84 coordinate system.

After creating models in 3D modelling software, they must be imported into software that puts them in interactive virtual environments and adds the elements needed to create a full VR application (rendering of 3D models, the virtual environment itself, control scheme, scripts, collision detection, physical models, animation, etc.). For this purpose, real-time engine software or web technologies can be used. The most commonly used real-time engines include Unreal Engine 4, Cry Engine (Germanchis et al., 2007; Shepherd and Bleasdale-Shepherd, 2009; Chądzyńska and Gotlib, 2015) and Unity (Kubíček et al., 2017; Stachoň et al., 2018). All three engines were primarily designed for creating computer games.

Web technologies that can provide VR are, for example, Three.js (Herman et al., 2017; Juřík et al., 2018), X3DOM (Herman and Řezník, 2015; Herman and Russnák, 2016) or WebVR. The advantage of web technologies is the fact that there is no need to install any new software application. Disadvantages of web technologies include both limited interaction capabilities (in most of them, virtual environments can be viewed only from a static point and cannot be moved through) and a reduction in the overall size of $3 \mathrm{D}$ models or whole virtual environments. For these reasons, we focused on the utilization of real-time engines; specifically, we used the Unity engine.

\section{DESIGN AND IMPLEMENTATION OF THE VIRTUAL ENVIRONMENT}

We designed and created a virtual environment called "Carthoreality". This environment is a virtual map room (see Fig. 4) that enables the user to go through, view different 3D maps and solve some tasks with the maps. Blender software 
with plug-in BlenderGIS, and the Unity game engine connected with Android Studio, were used for creation of Carthoreality. Carthoreality works on the Android platform (versions 7.0, 7.1 or 8.0) and it enables interactive movement. Users can browse through the environment by tilting the headset (tilting down activates walking, which moves the user forward; tilting up causes stopping of the movement; and the user can also look around). Selected elements in the map room are interactive. Interactive action, such as a label display, occurs when the user looks at it.

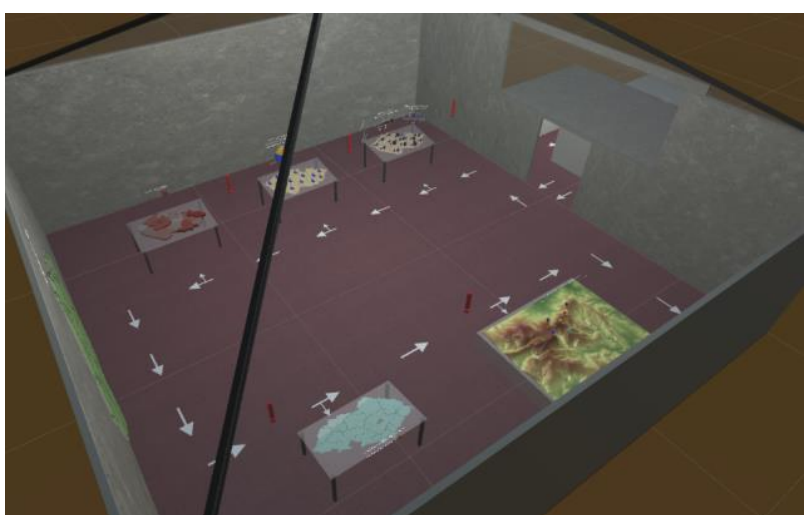

Figure 4. Overview of Carthoreality map room. It is displayed in Unity engine.

Carthoreality contains the following maps:

1. Agriculture and forestry in regions of the Czech Republic - 3D diagram map, simple proportional symbols (spheres, cubes and cones)

2. Employment in the economic sectors in the regions of the Czech Republic - diagram map with extruded pie charts

3. Population in regions of the Czech Republic - prism map

4. Overview map of the regions of the Czech Republic (interactive regions - the region name is displayed)

5. Number of immigrants in regions of the Czech Republic - dot map

6. Giant Mountains (Czech Republic) and their peaks surface map, terrain of selected area (interactive symbols of selected peaks - the name of the mountain and its altitude are displayed)

Maps are sorted in the order in which the user walks around when the suggested direction is delivered. Video showing Carthoreality walkthrough in virtual environment is available online at: https://youtu.be/4Mny2VyYD-E.

\section{PILOT EVALUATION}

We conducted simple pilot user testing using the Carthoreality virtual environment and the three devices mentioned above (Google Cardboard Splaks 3D VR, Homido VR, and BoboVR Z4). This user evaluation was designed as an exploratory one.

\subsection{Design, tasks and participants}

The pilot test was qualitative and based on within-subject design. Five people (three females and two males, aged between 20 and 51 years) participated in this study. Participants gradually tried all three compared devices in random order, rated these headsets and chose the most suitable based on headset's functionality, quality of construction and subjective feeling of comfort.

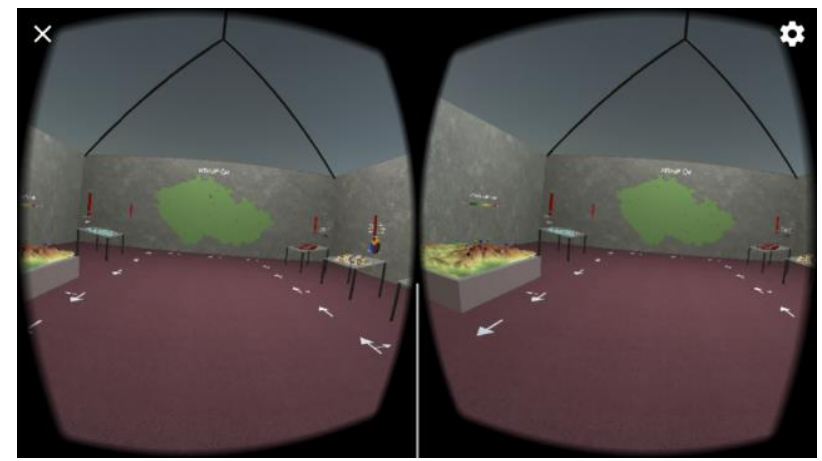

Figure 5. First-person view on Carthoreality. Screen is divided for display in a low cost headset.

Participants then used the most suitable device with the Carthoreality environment. Each user had to go through this environment along the marked route and respond to 14 questions, each one being solved using $3 \mathrm{D}$ visualisation. These tasks were:

- $\quad$ Tasks with pie chart map (Map n. 1)

- Which region or regions reach the highest values in at least two categories?

- In which region or regions is wood logging the most intensive?

- $\quad$ Tasks with pie chart map (Map n. 2)

- Which region has the largest share of the primary sector?

- Which region has the smallest share of the secondary sector?

- Which region has the largest share of the secondary sector?

- Which region has the largest share of the tertiary sector?

- $\quad$ Task with prism map (Map n. 3)

- Which region has the highest population?

- Which region has the lowest population?

- $\quad$ Task with dot map (Map n. 5)

- Which regions registered the most immigrants?

- Which regions registered the least immigrants?

- $\quad$ Task with surface map (Map n. 6)

- What colour is the symbol for "Luční hora"?

- What is the altitude of "Svorová hora"?

- What is the altitude of "Strríbrný hřbet"?

- What colour is the symbol for "Přední planina" and what is the altitude of this point?

Finally, they evaluated five "I" factors of Carthoreality (its interactivity, intensity, immersion, illustrativeness and intuitiveness) on a simple questionnaire. These factors were marked with values ranging from 1 (best) to 5 (worst). 


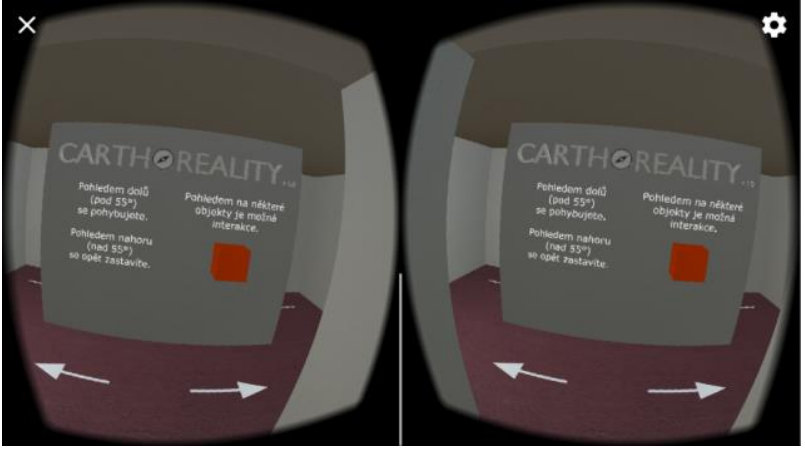

Figure 6. Instructions for control and interaction at the entrance to the virtual map room. Screen is divided for display in a low cost headset.

\subsection{Results}

All participants selected as the most suitable device the BoboVR Z4, which provides the most comfort during use, according to participants, and also isolates the display quite well from external light. By contrast, the worst was judged to be the Google Cardboard Splaks VR, whose paper construction caused considerable discomfort because the weight of the smartphone in this headset caused it not to hold well to the head. The user must hold this headset in his or her hands. There is also a problem with significant light transmission on the display. Homido VR was often rated similarly to BoboVR Z4, but it also posed the problem of penetrating light.

Only four participants completely passed the virtual environment, since the fifth was sick during testing and was unable to continue. Nausea during the wearing of headsets and disorientation after removing the headset have occurred for all users. This reaction could have been due to longer exposure to the virtual environment (length of stay in the environment was around 13 minutes) or absence of IMU. The overall experience, except for the nausea, was rated as positive by participants. There was no serious problem for them to orientate and move within the environment. If participants have any comments to the interaction with virtual environment, these were not essential. These minor comments were related to the speed of movement or the angle required for "activating" walking. There were not found to be any problems even with cartographic visualisations or solving tasks with $3 \mathrm{D}$ visualisations. All participants answered the questions correctly. Speed of user responses (efficiency) had not been evaluated due to the low number of participants.

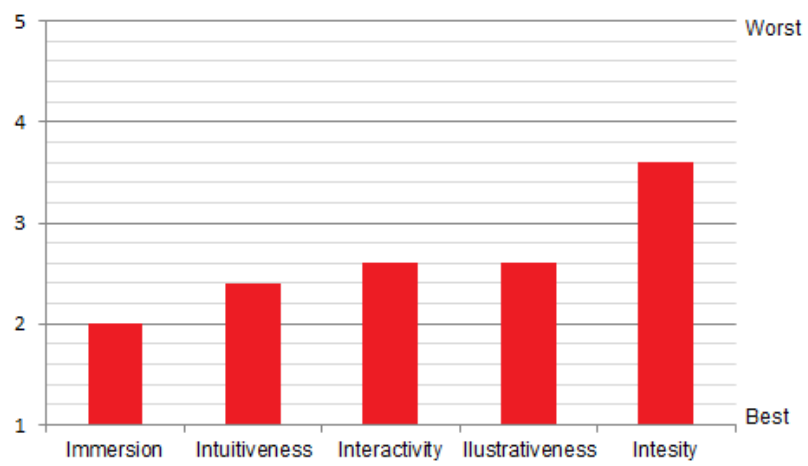

Figure 7. Results of satisfaction evaluation of "I" factors of Carthoreality.
In the final evaluation of Carthoreality (see Fig. 7), immersion was ranked as best in the term of satisfaction with this factor. However, such a good rating is due to the fact that it was the first experience with low-cost VR for all five participants. A similar assessment was also made for intuitiveness, interactivity and illustrativeness. On the other hand, the intensity of the whole experience was rated as the worst, which was negatively assessed by the user side, mainly due to the "too high intensity" causing nausea. In terms of all five aspects, there are opportunities for improvements, but this would require more powerful smartphones and also a more complex environment for future research.

\section{DISCUSSION AND CONCLUSIONS}

Cheaper headsets, though seemingly very similar to more expensive ones, are not well suited to long-term use. Their usage within education, for example, needs to be limited in time, given the varying degrees of nausea and disorientation that they tend to cause. These negative experiences can lead the unexperienced users to think they can not handle VR in general, even though a high-end headset (like Oculus Rift HMD) might eliminate those problems.

Cheap headsets are available, but they do not provide the most immersive or comfortable experience. Another problem is the performance of different processing units (smartphones) used in these low-cost headsets. The cheapest smartphones are usually not able to handle VR. In order to create virtual environments, combinations of different programs, both commercial and freely available or open source, can be used. Implementation of the Carthoreality project created in the open source program Blender and real-time engine Unity confirms these conclusions.

Carthoreality can be further developed and optimized, such as by involving more methods of cartographic visualisation or by adding functionality to capture answers to questions directly in the virtual environment (participants needed to answer verbally). The main limitation of our user study was the small number of participants; however, this testing was only exploratory, and therefore it was designed as qualitative. We believe that the abovementioned issues need to be addressed in future research studies.

\section{ACKNOWLEDGEMENTS}

This research was supported by projects "Influence of cartographic visualization methods on the success of solving practical and educational spatial tasks" (Grant No. MUNI/M/0846/2015) and "Integrated research on environmental changes in the landscape sphere of Earth III" (Grant No. MUNI/A/1251/2017).

\section{REFERENCES}

Bandrova, T., et al., 2012. Three-Dimensional Maps for Disaster Management. In Shortis, M., Madden, M. (eds.) ISPRS Annals of the Photogrammetry, Remote Sensing and Spatial Information Sciences, Vol. I-4. pp. 245-250. doi.org/10.5194/isprsannals-I-4-245-2012. 
Carbonell-Carrera, C., Saorín, J., 2017. Geospatial Google Street View with Virtual Reality: A Motivational Approach for Spatial Training Education. ISPRS International Journal of Geo-Information, 6(9), pp. 261-267. doi.org/10.3390/ijgi6090261.

Chądzyńska, D., Gotlib, D., 2015. Maps in Video Games Range of Applications. Polish Cartographical Review, 47(3), pp. 137-145. doi.org/10.1515/pcr-2015-0011.

Chmelík, J., Jurda, M., 2017. VEAAR - Virtual environment for archaeological artefacts restoration. In Spencer, S. N. (ed.) Proceedings of the ACM Symposium on Virtual Reality Software and Technology. doi.org/10.1145/3139131.3141780.

Coburn, J., et al., 2017. A Review of the Capabilities of Current Low-Cost Virtual Reality Technology and Its Potential to Enhance the Design Process. Journal of Computing and Information Science in Engineering, 17(3), pp. 1-15. doi.org/10.1115/1.4036921.

Faulkner, C., 2018. Samsung Gear VR review: The best VR headset for Samsung users.

http://www.techradar.com/reviews/samsung-gear-vr-2017 (2 July 2018).

Germanchis, T., et al., 2007. Virtual Queenscliff: A Computer Game Approach for Depicting Geography. In Cartwright, W., et al. (eds.) Multimedia Cartography. Berlin: Springer. pp 359368. doi.org/10.1007/978-3-540-36651-5_25.

Herbert, G., Chen, X., 2015. A Comparison of Usefulness of 2D and 3D Representations of Urban Planning. Cartography and Geographic Information Science, 42(1), pp. 22-32. doi.org/10.1080/15230406.2014.987694.

Herman, L., Russnák, J., 2016. X3DOM: Open Web Platform for Presenting 3D Geographical Data and E-learning. In Lněnička, L. (ed.) Central Europe Area in View of Current Geography. Proceedings of 23rd Central European Conference, pp. 31-40.

Herman, L., Řezník, T., 2015. 3D Web Visualization of Environmental Information - Integration of Heterogeneous Data Sources when Providing Navigation and Interaction. In Mallet, C., et al. (eds.) ISPRS Archives of the Photogrammetry, Remote Sensing and Spatial Information Sciences, Vol. XL3/W3, pp. 479-485. doi.org/10.5194/isprsarchives-XL-3-W3479-2015.

Herman, L., et al., 2017. Flood Modelling and Visualizations of Floods through 3D Open Data. In Schimak, G., et al. (eds.) Environmental Software Systems. Computer Science for Environmental Protection, pp. 139-149. doi.org/10.1007/978-3319-89935-0_12.

Juřík, V., et al., 2016. Cognitive Aspects of Collaboration in 3D Virtual Environments. In Halounova, L. et al. (eds.) ISPRS Archives of the Photogrammetry, Remote Sensing and Spatial Information Sciences, Vol. XLI-B2, pp. 663-670. doi.org/10.5194/isprsarchives-XLI-B2-663-2016.

Juřík, V., et al., 2017. When the Display Matters: A Multifaceted Perspective on 3D Geovisualizations. Open Geosciences, 9(1), pp. 89-100. doi.org/10.1080/17538947.2017.1382581.
Juřík, V., et al., 2018. Behavior Analysis in Virtual Geovisualizations: Towards Ecological Validity. In Bandrova, T., Konečný, M. (eds.) Proceedings, 7th International Conference on Cartography and GIS, Vol. 1, pp. 518-527.

Kovalčík, V., et al., 2012. Virtual Reality System as a Tool for Education. In Skála, V. (ed.) WSCG'2012 Poster Papers Proceedings. pp. 15-18.

Kubíček, P., et al., 2011. Flood Management and Geoinformation Support within the Emergency Cycle (EU Example). In Hřebíček, J., et al. (eds.) Environmental Software Systems. Frameworks of eEnvironment, pp. 77-86. doi.org/10.1007/978-3-642-22285-6_9.

Kubíček, P., et al., 2017. Identification of Altitude Profiles in 3D Geovisualizations: The Role of Interaction and Spatial Abilities. International Journal of Digital Earth, [in press] 118. doi.org/10.1080/17538947.2017.1382581.

Li, L., et al., 2017. Application of Virtual Reality Technology in Clinical Medicine. American Journal of Translational Research, 9(9), pp. 3867-3880.

Li, X., et al., 2015. XEarth: A 3D GIS Platform for Managing Massive City Information. In International Conference on Computational Intelligence and Virtual Environments for Measurement Systems and Applications. pp. 1-6. doi.org/10.1109/CIVEMSA.2015.7158625.

Liarokapis, F., et al., 2017 3D Modelling and Mapping For Virtual Exploration of Underwater Archaeology Assets. In Aguilera, D., et al. (eds.) ISPRS Archives of the Photogrammetry, Remote Sensing and Spatial Information Sciences, Vol. XLII-2/W3, pp. 425-431. doi.org/10.5194/isprsarchives-XLII-2-W3-425-2017.

Moskal, S., Choate, D., 2017. Examples of Implementing Google Cardboard in the Classroom. http://ctat.roanestate.edu/wp-content/uploads/Examples-ofImplementing-Google-Cardboard-in-the-Classroom_FinalVersion_4.25.17.pdf (1 July 2018).

Portman, M., et al., 2015. To Go Where No Man Has Gone Before: Virtual Reality in Architecture, Landscape Architecture and Environmental Planning. Computers, Environment and Urban Systems, 54(2015), pp. 376-384. doi.org/10.1016/j.compenvurbsys.2015.05.001.

Ripton, J. T., 2014. Google Cardboard: everything you need to know. http://www.techradar.com/news/phone-andcommunications/mobile-phones/google-cardboard-everythingyou-need-to-know-1277738 (3 July 2018).

Riva, G., 2006 Virtual Reality. In Akay, M. (ed.) Wiley Encyclopedia of Biomedical Engineering. pp 1-17. doi.org/10.1002/9780471740360.ebs1266.

Řezník, T., 2013. Geographic information in the age of the INSPIRE Directive: discovery, download and use for geographical research. Geografie, 118(1), pp. 77-93.

Shepherd, I. D. H., Bleasdale-Shepherd, I. D., 2009.

Videogames: the new GIS? In Lin, H., Batty, M. (eds.) Virtual Geographic Environments. Beijing: Science Press. pp. 311-344. 
Stachoň, Z., et al., 2018. The Role of Hue and Realism in Virtual Reality In Bandrova, T., Konečný, M. (eds.)

Proceedings, 7th International Conference on Cartography and GIS, Vol. 2, pp. 932-941.

Stojšić, I., et al., 2016. Possible Application of Virtual Reality in Geography Teaching. Journal of Subject Didactics, 1(2), pp. 83-96. doi.org/10.5281/zenodo.438169. 